\title{
Spatially resolved endogenous improved metabolite detection in human osteoarthritis cartilage by matrix assisted laser desorption ionization mass spectrometry imaging
}

Citation for published version (APA):

Eveque-Mourroux, M. R., Emans, P. J., Zautsen, R. R. M., Boonen, A., Heeren, R. M. A., \& Cillero-Pastor, B. (2019). Spatially resolved endogenous improved metabolite detection in human osteoarthritis cartilage by matrix assisted laser desorption ionization mass spectrometry imaging. Analyst, 144(20), 5953-5958. https://doi.org/10.1039/c9an00944b

Document status and date:

Published: 21/10/2019

DOI:

10.1039/c9an00944b

Document Version:

Publisher's PDF, also known as Version of record

\section{Document license:}

Taverne

\section{Please check the document version of this publication:}

- A submitted manuscript is the version of the article upon submission and before peer-review. There can be important differences between the submitted version and the official published version of record. People interested in the research are advised to contact the author for the final version of the publication, or visit the $\mathrm{DOI}$ to the publisher's website.

- The final author version and the galley proof are versions of the publication after peer review.

- The final published version features the final layout of the paper including the volume, issue and page numbers.

Link to publication

\footnotetext{
General rights rights.

- You may freely distribute the URL identifying the publication in the public portal. please follow below link for the End User Agreement:

www.umlib.nl/taverne-license

Take down policy

If you believe that this document breaches copyright please contact us at:

repository@maastrichtuniversity.nl

providing details and we will investigate your claim.
}

Copyright and moral rights for the publications made accessible in the public portal are retained by the authors and/or other copyright owners and it is a condition of accessing publications that users recognise and abide by the legal requirements associated with these

- Users may download and print one copy of any publication from the public portal for the purpose of private study or research.

- You may not further distribute the material or use it for any profit-making activity or commercial gain

If the publication is distributed under the terms of Article $25 \mathrm{fa}$ of the Dutch Copyright Act, indicated by the "Taverne" license above, 


\title{
Analyst
}

A) Check for updates

Cite this: Analyst, 2019, 144, 5953

\section{Spatially resolved endogenous improved metabolite detection in human osteoarthritis cartilage by matrix assisted laser desorption ionization mass spectrometry imaging $\dagger$}

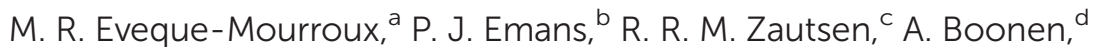 \\ R. M. A. Heeren (iD ${ }^{a}$ and B. Cillero-Pastor (iD *a
}

\begin{abstract}
Osteoarthritis $(O A)$ is one of the most common musculoskeletal diseases, characterized by the progressive deterioration of articular cartilage. Although the disease has been well studied in the past few years, the endogenous metabolic composition and more importantly the spatial information of these molecules in cartilage is still poorly understood. Matrix-assisted laser desorption/ionization (MALDI) mass spectrometry imaging (MSI) has been previously used for the investigation of the bimolecular distribution of proteins and lipids through the in situ analysis of cartilage tissue sections. MALDI-MSI as a tool to detect metabolites remains challenging, as these species have low abundance and degrade rapidly. In this work, we present a complete methodology, from sample preparation to data analysis for the detection of endogenous metabolites on cartilage by MSI. Our results demonstrate for the first time the ability to detect small molecules in fragile, challenging tissues through an optimized protocol, and render MSI as a tool towards a better understanding of $O A$.
\end{abstract}

Received 23rd May 2019

Accepted 9th August 2019

DOI: 10.1039/c9an00944b

rsc.li/analyst metabolomics or proteomics still remain essential to better understand the disease. ${ }^{9}$ However, these approaches require whole cartilage extracts and therefore they do not provide any spatial information of the biomolecules within the different layers of the tissue. One way to overcome this drawback is to use matrix-assisted laser desorption/ionization (MALDI) mass spectrometry imaging (MSI) technology.

MALDI-MSI allows for the investigation of the biomolecular distribution of proteins, lipids or metabolites through the analysis of a variety of tissue sections. ${ }^{10,11}$ For cartilage, studies have been conducted on lipids $^{12,13}$ and peptides. ${ }^{14-17}$ Nevertheless, the endogenous metabolic composition and more importantly the spatial information of these compounds have never been described. Amongst the matrices for metabolite detection, $N$-(1-naphthyl) ethylenediamine dihydrochloride (NEDC), 1,5-diaminonapthalene (DAN) and 9-aminoacridine (9AA) are the most commonly used in the field of MSI. ${ }^{18,19}$ These matrices exhibit very few matrix-related interferences in the low-mass range, which remains advantageous for the simultaneous detection of a variety of cellular metabolites in negative ion mode such as adenosine tri/di/mono/ phosphate compounds. ${ }^{20-22}$ MALDI-MSI applied to metabolites still remains challenging, especially due to the low abundance of these molecular species and their fast degradation. In addition, the low number of chondrocytes in the avascular, collagen rich extracellular matrix from cartilage tissue 
increases the difficulty to detect these compounds. As a consequence, an extensive sample preparation optimization (i) to avoid tissue degradation as much as possible and (ii) to increase extraction and detection of molecular signals by MALDI-MSI is required. Methods such as microwave irradiation $^{23,24}$ and freeze-blowing ${ }^{25}$ have been used in studies to prevent enzymatic tissue degradation. ${ }^{26}$ One alternative to these methods is the stabilizor system, a device able to preserve proteins ${ }^{27}$ or the phosphorylation state ${ }^{28}$ for tissue-based proteomic studies with a heat stabilization process. More interestingly, approaches using this technology have been recently applied to preserve amino neurotransmitters ${ }^{29}$ or metabolites $^{30}$ in MSI experiments on soft tissues. The application of this technology on cartilage can be combined with an optimized MALDI-MSI protocol in order to improve the detection of metabolites. However, protocol optimization remains timeconsuming, especially in MALDI-MSI experiments, and can lead to ambiguous results if the important parameters are not well established. One way to efficiently optimize a protocol is to use a statistical design of experiment approach. ${ }^{31-33}$ This approach reduces the number of experiments needed for protocol optimization and allows researchers to evaluate the influence of several parameters at once.

In this study, we demonstrated the possibility to extract metabolites from cartilage using 9AA matrix for the first time. These metabolites could be especially meaningful to assess the disease state of cartilage. The first experiments enabled us to evaluate the capabilities of the stabilizor system to permanently prevent biological changes from the moment of sampling. Then, a statistical design of experiments software was used to optimize the matrix deposition parameters in the MALDI-MSI workflow, in order to increase the detection of metabolites while retaining their spatial distribution. Finally, optimized imaging experiments were executed, revealing metabolite information from cartilage tissue that could previously not be retrieved.

\section{Experimental section}

\section{Sample preparation}

The Maastricht University Medical Centre institutional policy on the use of residual human surgical material states that no informed consent is needed in the case of residual surgical material. Human OA cartilage was obtained from three OA patients undergoing total knee joint replacement. Unwounded cartilage explants of $8 \times 8 \mathrm{~mm}$ were either heat stabilized by a stabilizor system (Denator, Uppsala) before freezing or immediately snap frozen and stored at $-80^{\circ} \mathrm{C}$. Snap-frozen tissues were sectioned at $12 \mu \mathrm{m}$ thickness with a cryostat (Leica Microsystems, Wetzlar) at $-20{ }^{\circ} \mathrm{C}$ and thaw mounted on cleaned indium tin oxide (ITO) glass slides (Delta Technologies, CO, USA).

\section{MALDI-MS profiling}

Ten $\mu \mathrm{L}$ of 9AA matrix (Sigma-Aldrich, Zwijndrecht, The Netherlands) was used (7 mg $\mathrm{mL}^{-1}$ in $70 \%$ Ethanol) for the extraction of metabolites from cartilage sections and analyzed in duplicate by MALDI-MS in negative ion mode. Norharmane matrix (Sigma-Aldrich) at $7 \mathrm{mg} \mathrm{mL}^{-1}$ in chloroform/methanol $(2: 1,(\mathrm{v} / \mathrm{v}))$ was used for lipid analysis in negative ion mode.

Metabolyte analysis was performed using a MALDI-FT-ICR-MS instrument (SolariX, Bruker Daltonik $\mathrm{GmbH}$, Bremen, Germany) at 300-600 $\mathrm{m} / \mathrm{z}$ with 230 laser shots at a laser repetition frequency of $2000 \mathrm{~Hz}$ and ion accumulation time of 5 milliseconds in the cell. Instrument external calibration was performed in negative ion mode using a standard calibration mixture of red phosphorous (Sigma-Aldrich). Instrument internal calibration was performed with reference masses of metabolites; adenosine monophosphate (AMP) at $\mathrm{m} / \mathrm{z}$ 346.0558, adenosine diphosphate (ADP) at $\mathrm{m} / \mathrm{z} 426.0221$ and adenosine triphosphate (ATP) at $m / z$ 505.9884, using FTMS Processing V2.1 (Bruker Daltonik GmbH) and Compass Isotope Pattern V3.0 (Bruker Daltonik $\mathrm{GmbH}$ ) to reach a mass error below 1 ppm.

Lipids were detected with norharmane matrix over the mass range $m / z$ 400-1400 Da using a Bruker RapifleX MALDI Tissue-typer instrument operating in reflectron mode.

MS/MS experiments were performed using a SYNAPT G2Si instrument (Waters Corporation, Manchester, UK) to confirm the identification of selected compounds.

\section{MALDI-MSI}

The HTX TM-Sprayer (HTX Imaging, Chapel Hill) was used to spray 9AA matrix for sample preparation. A SYNAPT G2Si instrument was used to compare the different protocols and acquire the imaging data over the mass range $\mathrm{m} / \mathrm{z} 100-1000$ in negative ion mode using the sensitivity mode and a scan time of 1 second per pixel. The Nd:YAG MALDI laser was operated at a firing rate of $1000 \mathrm{~Hz}$ with a lateral resolution of $100 \mu \mathrm{m}$. A SolariX FT-ICR-MS instrument was used to validate the experimental model in imaging mode. FT-ICR MSI data was acquired with a lateral resolution of $40 \mu \mathrm{m}$. Ion accumulation time in the cell was set up at 5 milliseconds and 400 laser shots at a laser repetition frequency of $2000 \mathrm{~Hz}$ were used.

\section{Data analysis}

Compass DataAnalysis software V4.4 and FTMS Processing V2.1 were used to visualize the mass spectra and to calculate the signal to noise for each metabolite of interest in profiling mode.

For the experimental design approach, acquired data were processed and analyzed using HDI Imaging software V1.4 (Waters Corporation) by extracting the 1000 most abundant ions with the following settings: $\mathrm{m} / \mathrm{z}$ window $=0.02 \mathrm{Da}$ and MS resolution $=15000$. Intensities were normalized by Total Ion Count (TIC) and Regions Of Interest (ROIs) were manually created. Finally, intensities of ATP, ADP and UDP from these ROIs were used for elaborating the experimental design response variables as input into Aexd.net (Alleviating Science). ${ }^{34}$

Aexd.net was used to generate an experimental design in a six steps approach: (i) creation of the first experimental design table, (ii) acquisition of the data through the first set of experi- 
ments and data input into the dedicated software, (iii) statistical analysis of the results with generation of a model and definition of significant parameters of the HTX TM-Sprayer, (iv) creation of the second experimental design table, (v) acquisition of the data through the second set of experiments and data input into the software, (vi) statistical analysis and visualization of the final results. The experimental design used a Plackett-Burman (PB-12 + 3) design followed by a surface response analysis of a central composite rotatable design (CCRD $2^{\wedge} 2+2 \times 2+3$ ). Importantly, the step vi allowed the creation of regression models for each response variable to describe the influence of variation in the dependent variables on the response variables. The parameters of the HTX TM-Sprayer used in the experimental design were: temperature, flow rate, drying time, number of layers, matrix concentration and percentage of solvent used to dissolve the matrix.

SCiLS lab 2019b software was used to calculate the metabolite intensities inside and outside the tissues (SCiLS lab, GmbH, Bremen, Germany) after root mean square (RMS) normalization for the imaging experiments acquired by FT-ICR-MS. The sqlite files generated were converted at a bin size of $\mathrm{m} / \mathrm{z} 0.001$ to MATLAB 2016b (The MathWorks, Natick, USA) and in-house developed PEAPI software ${ }^{35}$ was then used for peak-picking.

Finally, principal component analysis (PCA) followed by cluster analysis were applied to study the spatial metabolic distribution using an in-house ChemomeTricks toolbox for MATLAB. The Human Metabolome Database (HMDB) V4.0 and METLIN software V3.7.1 were used for molecular assignments with a tolerance up to $1 \mathrm{ppm}$. Drugs and exogenous compounds were automatically excluded for the assignments.

\section{Histological staining}

Safranin O staining was used to discriminate between superficial and deep cartilage. The matrix was removed by immersion in $70 \%$ ethanol and the sections were then stained using hematoxylin (Sigma-Aldrich) for $8 \mathrm{~min}$, Safranin O (SigmaAldrich) $0.1 \%$ dissolved in ultrapure $\mathrm{H}_{2} \mathrm{O}$ for $2 \mathrm{~min}$ and Fast Green FCF (Sigma-Aldrich) $0.1 \%$ dissolved in ultrapure $\mathrm{H}_{2} \mathrm{O}$ for $4 \mathrm{~min}$. Finally, digital images were acquired with the Mirax desk slide scanner V2.6 software (Carl Zeiss, Gottingen, Germany) after dehydrating steps.

\section{Results and discussion}

\section{Heat stabilization slows-down the degradation of endogenous metabolites on cartilage}

We evaluated the capability of heat stabilization to preserve the integrity of different endogenous metabolites when using 9AA matrix. Results showed for the first time the detection of nucleotides and nucleotide sugars from human cartilage tissue using 9AA (Fig. 1). UTP was only detected when the samples were heat-stabilized before being snap frozen.

When the samples were heat-stabilized, the observed metabolic patterns changed dramatically with a gain of sensitivity

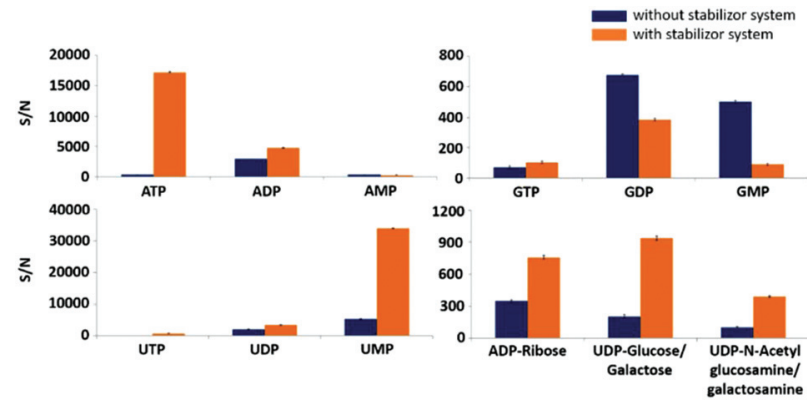

Fig. 1 Metabolite detection on cartilage and their slowed-down degradation using the stabilizor system.

except for GDP and GMP. However the triphosphate form (GTP) was detected 1.5 fold enhanced after heat stabilization. Interestingly, these experiments showed that triphosphate analytes (UTP, GTP and mostly ATP) were well-preserved after heat stabilization. A previous study showed and confirmed that the inactivation of the proteolytic activity preserves the metabolic state better, which is in line with our data. ${ }^{36}$ This improved preservation allowed us to perform MS/MS fragmentation to identify the detected compounds (ESI Table $1 \dagger$ ). ATP, ADP, AMP, UDP and ADP-Ribose were assigned due to the presence of two or more specific fragments. ${ }^{37}$

Complementary data showed the possibility to detect enhanced intensities of lipid species. As an example, the $\mathrm{m} / \mathrm{z}$ at 885.5 was three fold enhanced when using norharmane on heat stabilized cartilage samples (Fig. 2). $885.5 \mathrm{~m} / \mathrm{z}$ was identified as phosphatidylinositol $\left[\mathrm{PI}\left(18: 0 \_20: 4\right)-\mathrm{H}\right]^{-}$, a well-known lipid detectable from a large variety of tissues in MSI experiments. $^{38-40}$ These data indicate that the use of the stabilizor system boosts the detection of other biomolecular classes.

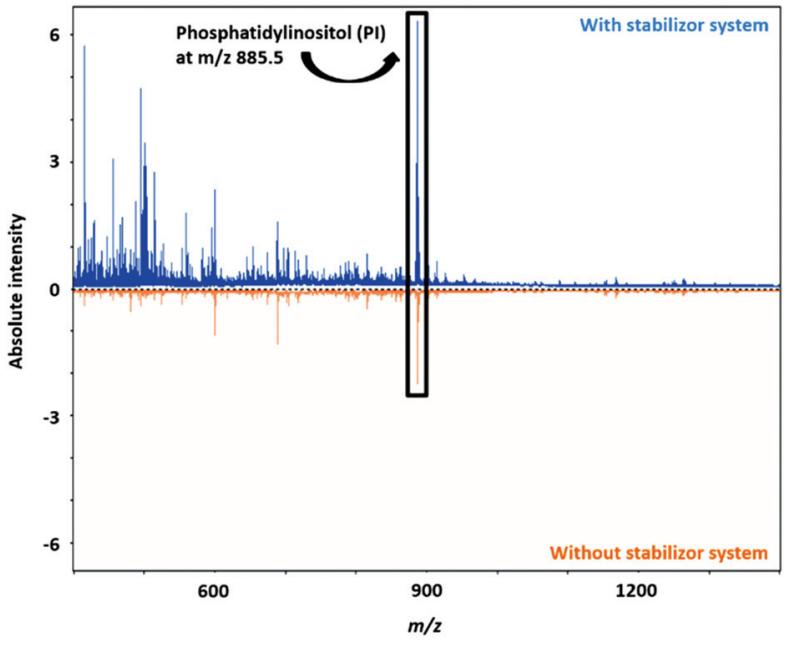

Fig. 2 Profiling experiment with norharmane matrix in negative ion mode showed an enhanced lipid spectra when using the stabilizor system. 
Experimental design for metabolite detection on cartilage

Although profiling experiments showed interesting results using the stabilizor system such as higher intensities and better preservation of metabolic compounds, direct on-tissue detection of these species using MSI still remains challenging. This is mainly due to the low abundance of metabolites in contrast to other analytes such as lipids and the well-known ion suppression effect. ${ }^{41}$ In addition, metabolite extraction for profiling experiments was performed using a very wet method, prone to compound delocalization, which is not suitable for imaging as the spatial distribution of the metabolites needs to be preserved. Therefore, method optimization for the detection of metabolites by MALDI-MSI is needed, especially considering the number of parameters to test in an imaging experiment. We applied this design of experiment strategy by optimizing the HTX TM-Sprayer settings (temperature, flow rate, drying time, number of layers, matrix concentration and percentage of solvent used to dissolve the matrix) as independent variables utilizing Aexd.net (ESI Table $2 \dagger$ ) to improve the detection of metabolites on cartilage by MALDI-MSI. We evaluated the effects of these six independent variables on the overall imaging data quality which included (i) the metabolite intensities within the tissue as well as (ii) the delocalization outside the cartilage. A total of two response variables ( $\mathrm{i}$ and ii) were then defined based on averages of ATP, ADP and UDP intensities on cartilage due to their overall good detectability in the profiling experiments. ROIs corresponding to tissue areas were created to calculate metabolite intensities within the tissues (i). Based on the imaging data, ROIs were also created at $5 \mathrm{~mm}$ of distance from the edge of the sample to evaluate the analyte diffusion (ii) with an average number of 1200 pixels per region. The ratio between the average intensity of ATP, ADP and UDP inside (i)/outside the tissue defined the de-localization (ii). Final calculated values for each experiment were entered in the software to statistically define the most significant independent variables. Defining multiple response variables did not increase the number of experiments to be executed, but augmented the probability of achieving a valid prediction model: if a regression model can be established for at least one of these response variables, optimal settings of the independent variables can be predicted from that model. The final approach is described in Fig. 3. Briefly, a first step of 15 experiments performed in duplicate was designed to determine the significant settings of the HTX TM-Sprayer, meaning the settings influencing the most on (i) the metabolite intensities within the tissue and on (ii) the spatial distribution of these metabolites. In this way response variables were based on either metabolite intensity or spatial distribution. A second set of experiments was subsequently conducted to optimize these significant settings and increase the sensitivity for metabolite detection while preserving their spatial information as much as possible. Results from the first set of experiments showed that EtOH percentage was the most significant parameter influencing the quality of the data, meaning high intensity and good spatial preservation (Fig. $4 \mathrm{a}$ and b). The $t$-values $(t(8)$

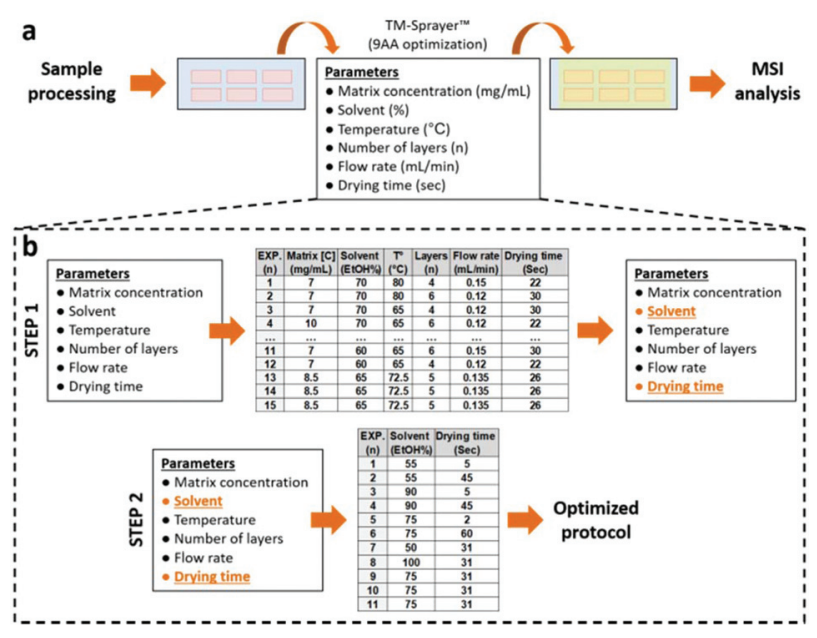

Fig. 3 MSI workflow optimization for metabolite detection on cartilage using an experimental design approach. (a) Standard MSI workflow. (b) Schematic of the experimental design approach.
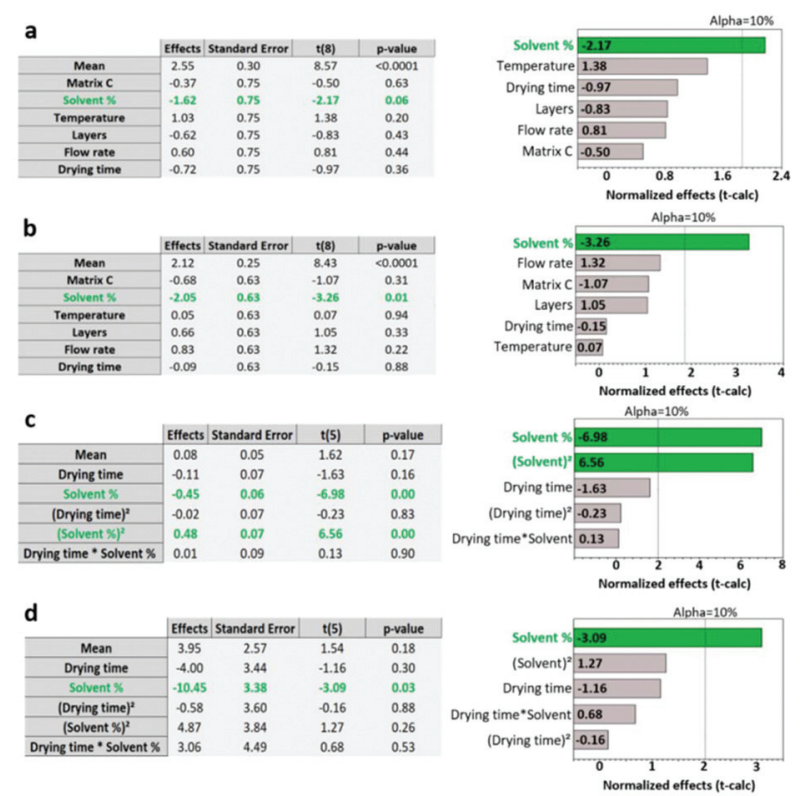

Fig. 4 Effects of the HTX TM-Sprayer settings on the metabolite intensities inside the tissue (a) and their delocalization outside the tissue (b) in the first step of the experimental design. The same statistics were applied to the second step of the experimental design (c and d).

and $t(5))$ represent the effect divided by the standard error. The effects are estimated alterations of the response-variable caused by changes of independent variables (concentration of matrix, percentage of solvent, temperature, layers, flow rate and drying time). Squared factors as (drying time)2 and (Solvent \%)2 are factors responsible for the curvature of the model. We decided to add the drying time to the second step as an independent variable to verify if the statistical non-significance of this feature could be confirmed or negated for a wider value range. This second step was conducted on 11 experiments. Three different solvent percentages $(50,75$ and 
100) as well as three different drying times (2, 31 and 60 seconds) were used as lower, center, and high values, respectively. As the other parameters were not significant, fixed values were chosen based on the first step (ESI Table $2 \dagger$ ). The same response variables were used as described in the first step. Results showed that EtOH percentage for the solvent used for the matrix is still a significant parameter, confirming results of the first step of 15 experiments (Fig. 4c and d). The drying time still appeared to be statistically non-significant (Fig. 4c and d).

\section{Validation of the experimental design on cartilage metabolic distribution}

In order to validate our approach, three experiments on consecutive sections were carried out in duplicate using FT-ICR instrument with different solvent percentages and drying times within the range of the experimental design (Fig. 5a). The other settings from the HTX TM-Sprayer were set-up as depicted in the step 2 of the ESI Table 2. $\dagger$ All three experiments showed more intensity inside than outside the tissue according to the calculated ratios (Fig. 5b, ESI Fig. 1 and $2 \dagger$ ). From these, experiments 1 and 2 showed similar results in terms of metabolite intensity confirming that drying time had no significant effect (ESI Fig. $1 \dagger$ ). Experiments using 50\% EtOH showed a better metabolite extraction than using 55\% EtOH. These results confirmed the significance of the solvent percentage in the detection of metabolite species. In addition to this validation, PCA and clustering analysis showed here for the first time the specific metabolic distribution of a cluster of species (ATP, ADP, AMP, UDP, UMP, GDP, GMP and ADPribose) in human cartilage (Fig. $5 \mathrm{~b}$ and c).

a
\begin{tabular}{|c|c|c|c|c|}
\hline \multirow{2}{*}{ TM-SPRAYER ${ }^{\mathrm{m}}$ Settings } & \multirow{2}{*}{ Unit } & \multicolumn{3}{|c|}{ Experiments (in duplicate) } \\
\cline { 3 - 5 } & & $\mathbf{1}$ & $\mathbf{2}$ & $\mathbf{3}$ \\
\hline Drying time & $\mathrm{sec}$ & 5 & 45 & 30 \\
\hline Solvent & $\%$ & 55 & 55 & 50 \\
\hline Temperature & ${ }^{\circ} \mathrm{C}$ & \multicolumn{3}{|c|}{80} \\
\hline Number of layers & $\mathrm{N}$ & \multicolumn{3}{|c|}{0.1} \\
\hline Flow rate & $\mathrm{mL} / \mathrm{min}$ & \multicolumn{3}{|c}{10} \\
\hline Matrix Concentration & $\mathrm{mg} / \mathrm{mL}$ & \multicolumn{3}{|c|}{} \\
\hline
\end{tabular}

b

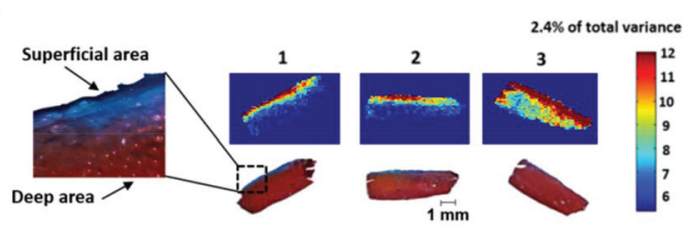

c

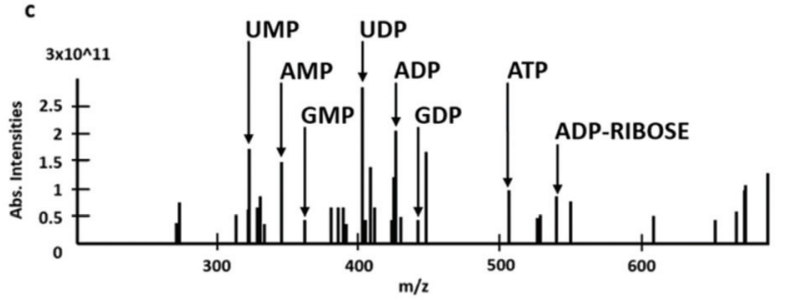

Fig. 5 Model validation based on MALDI-FT-ICR data. (a) HTX settings used to validate the experimental design model. (b) Cluster images with the subsequent stained tissue. (c) Reconstructed cluster spectrum.
In particular the experiments 1 and 2 demonstrated that this panel of metabolites are distributed in the superficial area of the human OA cartilage when compared to the histological safranin $\mathrm{O}$ staining (Fig. 5b). This result showed the importance of the safranin $\mathrm{O}$ staining for accurate co-registration with the MSI data. This specific distribution is in particular relevant since the superficial area of the cartilage is in close contact with the synovial fluid and it's the only zone where articular cartilage progenitor cells have been found. ${ }^{42} 50 \%$ EtOH seemed to improve the extraction of metabolites but compromising the intra-tissue spatial heterogeneity and therefore resulting in intra-tissue metabolic de-localization (Fig. 5b). Here, the data showed that ethanol percentage and drying time might be critical to keep the spatial intra-tissue metabolic distribution, meaning to differentiate superficial and deep areas of the cartilage. Another experimental design model should be considered to statistically validate this hypothesis. Based on our results, methods 1 and 2 are equally optimal to study the metabolic spatial distribution in cartilage.

\section{Conclusions}

To the best of our knowledge, this is the first study that reports the detection of endogenous metabolites in cartilage using MALDI-MSI. We showed the efficiency of heat stabilization to preserve endogenous metabolites within the cartilage and demonstrated for the first time the potential of experimental design to optimize MALDI-MSI sample preparation protocols. Especially, the optimized results revealed a higher presence of metabolites in the superficial area of the cartilage. This method could be employed to further study metabolic spatial abnormalities in human OA cartilage.

\section{Conflicts of interest}

There are no conflicts to declare.

\section{Acknowledgements}

The work was performed as part of the M4I research program that was financially supported by the Dutch Province of Limburg through the "LINK" program and by the MUMC institutional grant for clinical collaborative research.

\section{Notes and references}

1 A. B. Gonzalez Gil, R. Llombart Blanco and P. Diaz de Rada, Rev. Esp. Cir. Ortop. Traumatol., 2015, 59, 281-286.

2 C. G. Helmick, D. T. Felson, R. C. Lawrence, S. Gabriel, R. Hirsch, C. K. Kwoh, et al., Arthritis Rheum., 2008, 58, 15-25.

3 T. Vos, A. A. Abajobir, C. Abbafati, K. M. Abbas, K. H. Abate, F. Abd-Allah, et al., Lancet, 2017, 390, 12111259. 
4 P. Bhattaram and U. Chandrasekharan, Semin. Cell Dev. Biol., 2017, 62, 86-93.

5 H. J. Braun and G. E. Gold, Bone, 2012, 51, 278-288.

6 A. Hasegawa, S. Otsuki, C. Pauli, S. Miyaki, S. Patil, N. Steklov, et al., Arthritis Rheum., 2012, 64, 696-704.

7 O. M. Aho, M. Finnila, J. Thevenot, S. Saarakkala and P. Lehenkari, PLoS One, 2017, 12, e0173726.

8 A. Mobasheri, M. P. Rayman, O. Gualillo, J. Sellam, P. van der Kraan and U. Fearon, Nat. Rev. Rheumatol., 2017, 13, 302-311.

9 C. Ruiz-Romero, I. Rego-Perez and F. J. Blanco, Curr. Opin. Rheumatol., 2018, 30, 114-120.

10 J. L. Norris and R. M. Caprioli, Chem. Rev., 2013, 113, 2309-2342.

11 R. M. Caprioli, T. B. Farmer and J. Gile, Anal. Chem., 1997, 69, 4751-4760.

12 B. Rocha, B. Cillero-Pastor, G. Eijkel, A. L. Bruinen, C. RuizRomero, R. M. Heeren, et al., Proteomics, 2015, 15, 702-713.

13 B. Cillero-Pastor, G. Eijkel, A. Kiss, F. J. Blanco and R. M. A. Heeren, Anal. Chem., 2012, 84, 8909-8916.

14 B. Cillero-Pastor, G. B. Eijkel, F. J. Blanco and R. M. Heeren, Anal. Bioanal. Chem., 2015, 407, 22132222.

15 B. Cillero-Pastor and R. M. Heeren, J. Proteome Res., 2014, 13, 325-335.

16 M. J. Peffers, B. Cillero-Pastor, G. B. Eijkel, P. D. Clegg and R. M. Heeren, Arthritis Res. Ther., 2014, 16, R110.

17 B. Cillero-Pastor, G. B. Eijkel, A. Kiss, F. J. Blanco and R. M. Heeren, Arthritis Rheum., 2013, 65, 710-720.

18 S. R. Fagerer, S. Nielsen, A. Ibanez and R. Zenobi, Eur. J. Mass Spectrom., 2013, 19, 39-47.

19 C. D. Cerruti, F. Benabdellah, O. Laprevote, D. Touboul and A. Brunelle, Anal. Chem., 2012, 84, 2164-2171.

20 A. Amantonico, J. Y. Oh, J. Sobek, M. Heinemann and R. Zenobi, Angew. Chem., Int. Ed., 2008, 47, 5382-5385.

21 S. Vaidyanathan and R. Goodacre, Rapid Commun. Mass Spectrom., 2007, 21, 2072-2078.

22 O. Guillaume-Gentil, T. Rey, P. Kiefer, A. J. Ibanez, R. Steinhoff, R. Bronnimann, et al., Anal. Chem., 2017, 89, 5017-5023.

23 M. Hennebelle, A. H. Metherel, A. P. Kitson, Y. Otoki, J. Yang, K. S. S. Lee, et al., J. Lipid Res., 2019, 60, 671-682.
24 S. M. Alashmali, A. P. Kitson, L. Lin, R. J. S. Lacombe and R. P. Bazinet, Nutr. Neurosci., 2017, 1-12, DOI: 10.1080/ 1028415X.2017.1372160.

25 R. J. Pawlosky, Y. Kashiwaya, S. Srivastava, M. T. King, C. Crutchfield, N. Volkow, et al., Alcohol.: Clin. Exp. Res., 2010, 34, 375-381.

26 E. J. Murphy, Prostaglandins Other Lipid Mediators, 2010, 91, 63-67.

27 M. Svensson, M. Boren, K. Skold, M. Falth, B. Sjogren, M. Andersson, et al., J. Proteome Res., 2009, 8, 974-981.

28 M. Boren, Methods Mol. Biol., 2017, 1554, 143-153.

29 C. Esteve, E. A. Tolner, R. Shyti, A. M. van den Maagdenberg and L. A. McDonnell, Metabolomics, 2016, $12,30$.

30 F. P. Y. Barre, B. S. R. Claes, F. Dewez, C. Peutz-Kootstra, H. F. Munch-Petersen, K. Gronbaek, et al., Anal. Chem., 2018, 90, 14198-14206.

31 R. E. Caffrey, Methods Mol. Biol., 2010, 641, 167-183.

32 D. B. Hibbert, J. Chromatogr. B: Anal. Technol. Biomed. Life Sci., 2012, 910, 2-13.

33 F. Duke and K. Jen, Lab. Anim., 2016, 45, 14.

34 Aexd.net, version 1.0.32, Alleviating Science, Heerlen, The Netherlands, 2018; software available at https://aexd.net.

35 G. B. Eijkel, B. K. Kaletas, I. M. van der Wiel, J. M. Kros, T. M. Luider and R. M. A. Heeren, Surf. Interface Anal., 2009, 41, 675-685.

36 E. Q. Blatherwick, C. I. Svensson, B. G. Frenguelli and J. H. Scrivens, Int. J. Mass Spectrom., 2013, 345, 19-27.

37 T. Morikawa-Ichinose, Y. Fujimura, F. Murayama, Y. Yamazaki, T. Yamamoto, H. Wariishi, et al., J. Am. Soc. Mass Spectrom., 2019, 30, 1512-1520.

38 J. Hartler, R. Tharakan, H. C. Kofeler, D. R. Graham and G. G. Thallinger, Briefings Bioinf., 2013, 14, 375-390.

39 L. J. Sparvero, A. A. Amoscato, C. E. Dixon, J. B. Long, P. M. Kochanek, B. R. Pitt, et al., Chem. Phys. Lipids, 2012, 165, 545-562.

40 T. Hiraide, K. Ikegami, T. Sakaguchi, Y. Morita, T. Hayasaka, N. Masaki, et al., Sci. Rep., 2016, 6, 29935.

41 A. J. Taylor, A. Dexter and J. Bunch, Anal. Chem., 2018, 90, 5637-5645.

42 Y. Z. Huang, H. Q. Xie, A. Silini, O. Parolini, Y. Zhang, L. Deng, et al., Stem Cell Rev., 2017, 13, 575-586. 